\begin{tabular}{|c|c|}
\hline Title & $\begin{array}{l}\text { Nitrobenzene assisted reduction of pheny lacetylene with hy drazine over nitrogen-doped metal-free activ ated carbon } \\
\text { cataly st: Significance of interactions among substrates and catalyst }\end{array}$ \\
\hline Author(s) & Fujita, Shin-ichiro; A sano, Say aka; A rai, Masahiko \\
\hline Citation & $\begin{array}{l}\text { Journal of molecular catalysis a chemical, 423, 181-184 } \\
\text { https://doi.org/10.1016/.molcata.2016.06.022 }\end{array}$ \\
\hline Issue Date & 2016-11 \\
\hline Doc URL & http:/hdl. handle.net/2115/71763 \\
\hline Rights & $\begin{array}{l}\text { (9 2016. This manuscript version is made available under the CC-BY-NC-ND } 4.0 \text { license } \\
\text { http://reativecommons.org/icenses/by-nc-nd/4.0/ }\end{array}$ \\
\hline Rights(URL) & http://creativecommons.org/icenses/by-nc-nd/4.0/ \\
\hline Type & article (author version) \\
\hline File Information & A rai-JMC-A C423.pdf \\
\hline
\end{tabular}

Instructions for use 


\title{
Nitrobenzene-assisted reduction of phenylacetylene with hydrazine over nitrogen-doped metal-free activated carbon catalyst: \\ Significance of interactions among substrates and catalyst
}

\author{
Shin-ichiro Fujita, Sayaka Asano, Masahiko Arai*
}

Division of Applied Chemistry, Faculty of Engineering, Hokkaido University, Sapporo 060-8628, Japan

* Corresponding author. Fax: +81 11706 6594. E-mail address: marai@eng.hokudai.ac.jp

\begin{abstract}
A nitrogen-doped activated carbon (AC) can catalyze the reduction of nitrobenzene with hydrazine but not phenylacetylene. When nitrobenzene coexists in the reaction mixture, however, phenylacetylene can also be reduced. Nitrobenzene is likely to assist the adsorption of phenylacetylene on the surface of AC catalyst through molecular interactions between the two substrates, allowing their simultaneous reduction to aniline and styrene. For these interactions to occur, nitrogen and/or oxygen species doped on the surface of AC are involved. The results demonstrate a new interesting catalytic function of nitrogen- and oxygen-doped metal-free carbon materials.
\end{abstract}

\section{KEYWORDS:}

Carbon, Nitrogen doping, Reduction, Phenylacetylene, Nitrobenzene 


\section{Introduction}

The doping of nitrogen to carbon materials attracts increasing attention as an interesting and effective method for modifying, improving, and creating their chemical functions. Different methods of nitrogen doping have been reported, as demonstrated in recent review articles [1-6], including chemical vapor deposition, polymerization using nitrogen-containing compounds such as acetonitrile, pyridine, cyanide, and melamine, and others. Those nitrogen-doped metal-free carbon materials (carbon nitride in some cases) are active catalysts for various reactions such as Knoevenagel condensation, transesterification, Friedel-Crafts reaction, cyclization, coupling of carbon dioxide and epoxide, and oxidation. In addition, theoretical consideration suggests that the doping of nitrogen species modify the electronic structure of neighboring carbon atoms and deliver new catalytic functions on the surface of carbon materials [7]. Thus, the nitrogen-doped carbon materials are expected to act as metal-free multi-functional catalysts useable for various chemical transformations that are usually catalyzed by various metal and metal oxide catalysts.

The present authors prepared nitrogen-doped carbon materials by a simple method in which an activated carbon (AC) was treated by a mixture of ammonia and air at temperatures of $400-800^{\circ} \mathrm{C}$. Those nitrogen-doped AC materials were shown to catalyze different types of organic reactions including Knoevenagel condensation [8, 9], transesterification [8], reduction [10], and oxidation [11, 12]. One of interesting results obtained is chemoselectivity in the reduction of aromatic substrates by hydrazine [10]. It was indicated that nitrogen and oxygen species existing on the surface of AC did serve as active sites for this reduction. Nitrobenzene was reduced to aniline but not styrene; however, vinyl group, as well as nitro group, of 3-nitrostyrene was reduced. It is assumed that the adsorption of nitrobenzene and 3-nitrostyrene occurs on the surface of nitrogen-doped AC through interactions of their nitro group with the catalyst. In the following course of study on the catalysis of nitrogen-doped AC materials, other interesting features have been obtained in the reduction of phenylacetylene and other organic substrates by hydrazine. Phenylacetylene cannot be reduced, similar to styrene, but its reduction can occur by the coexistence of reducible nitrobenzene. These results will be reported in the present work. 


\section{Experimental}

A selected nitrogen-doped AC sample was used as a catalyst, which was prepared by treating a commercial AC (from GL Science, having a BET surface area of $1047 \mathrm{~m}^{2} \mathrm{~g}^{-1}$ and an $\mathrm{O}$ content of $10 \%$ ) with hydrogen peroxide at $130^{\circ} \mathrm{C}$ and then with ammonia at $800^{\circ} \mathrm{C}$ $[10,12]$. The AC sample so prepared was found to have a BET surface area of $1198 \mathrm{~m}^{2} \mathrm{~g}^{-1}$ and contain $\mathrm{N}$ and $\mathrm{O}$ species in $3.1 \%$ and $5.3 \%$, respectively, from XPS measurements. The reduction of phenylacetylene was conducted with this catalyst in an autoclave at $100^{\circ} \mathrm{C}$ in the same procedures as described elsewhere [10] and styrene and ethylbenzene were observed to form as products under the conditions used.

The possibility of molecular interactions between phenylacetylene and nitrobenzene was examined by FTIR spectroscopy in attenuated total reflection (ATR) mode [13]. The measurements were made for phenylacetylene, nitrobenzene, and their mixture in 1:1 in volume at room temperature. The FTIR - ATR spectra were also collected at a reaction temperature of $100^{\circ} \mathrm{C}$ and the spectra obtained were the same as obtained at room temperature.

\section{Results and discussion}

Table 1 shows the influence of different organic additives on the reduction of phenylacetylene. Under the conditions used, nitrobenzene was observed to transform to aniline exclusively. The conversion obtained in the absence of any additive was $6 \%$ (entry 1 ) and comparable small conversion values were also obtained with benzyl cyanide, benzaldehyde, and aniline (entries 2, 3, 5). It is interesting, in contrast, that an enhanced conversion of $28 \%$ was achieved in the presence of nitrobenzene (entry 4). Although reducible nitrobenzene and benzaldehyde gave similar conversion values of $89 \%$ and $100 \%$, respectively, the former promoted the reduction of phenylacetylene but not the latter. In addition, further reduction of the first-step product of styrene to ethylbenzene was promoted by nitrobenzene compared to benzaldehyde (entries 3,4). For comparison, the parent unmodified AC sample was used instead of the nitrogen-doped one. When nitrobenzene and phenylacetylene was reacted alone, the conversion was observed to be $27 \%$ and $6 \%$, 
respectively, under the same conditions as used for Table 1. Even when nitrobenzene was also present in the reaction mixture, the conversion of phenylacetylene was not enhanced. It is important to note that the promotional effect of coexisting nitrobenzene on the reduction of phenylacetylene appears in the presence of the nitrogen-doped AC sample.

\section{Table 1}

Reduction of phenylacetylene (PA) to styrene (ST) by hydrazine over nitrogen-doped AC catalyst in the presence of organic additives

\begin{tabular}{ccccc}
\hline Entry & Additive & $\begin{array}{c}\text { Conversion of } \\
\text { additive }(\%)\end{array}$ & $\begin{array}{c}\text { Conversion of PA } \\
(\%)\end{array}$ & $\begin{array}{c}\text { Selectivity to ST } \\
(\%)\end{array}$ \\
\hline 1 & - & - & 6 & 91 \\
2 & Benzyl cyanide & 0 & 4 & 88 \\
3 & Benzaldehyde & 100 & 7 & 85 \\
4 & Nitrobenzene & 89 & 28 & 64 \\
5 & Aniline & 0 & 8 & 76 \\
\hline
\end{tabular}

Reaction conditions: catalyst $10 \mathrm{mg}$, phenylacetylene $0.5 \mathrm{~cm}^{3}$, additive $0.5 \mathrm{~cm}^{3}$, hydrazine $4.0 \mathrm{~cm} 3$, $\mathrm{N}_{2} 0.2 \mathrm{MPa}, 100^{\circ} \mathrm{C}, 2 \mathrm{~h}$.

Next, the reduction of phenylacetylene was conducted in the presence of different amounts of nitrobenzene. The total volume of reaction mixture and the concentration of phenylacetylene were fixed by using ethylene glycol as a diluent. The conversion of nitrobenzene was controlled to be $<25 \%$ by using a short reaction time of $20 \mathrm{~min}$ in order to avoid the influence of a significant change in the nitrobenzene concentration in the liquid phase. Under the conditions used, styrene, ethylbenzene, and aniline were observed to form as products (Scheme 1). Nitrobenzene was hydrogenated to aniline in $100 \%$ selectivity. The results obtained are shown in Table 2 and Fig. 1. The non-catalytic reduction of phenylacetylene alone occurred to a small extent and the nitrogen-doped AC catalyst was inactive (entries 1,6). When nitrobenzene was added, the conversion of phenylacetylene was enhanced and the enhancement was even more significant in the presence of catalyst than in the absence of catalyst. That is, the nitrogen-doped AC catalyst is involved in the reduction 
of phenylacetylene assisted by nitrobenzene. The results show that the reduction of phenylacetylene is not further promoted by increasing the amount of nitrobenzene from 0.5 $\mathrm{cm}^{3}$, at which molar ratio of nitrobenzene against phenylacetylene $\left(0.25 \mathrm{~cm}^{3}\right)$ is ca. 2 . Table 2 indicates that the selectivity to styrene is a little smaller in the presence of nitrogen-doped AC catalyst than in the absence of the catalyst. This is due to a larger conversion obtained in the presence of the catalyst. As shown later (Fig. 2), the selectivity to styrene is decreasing with reaction time, namely, with an increase in conversion.

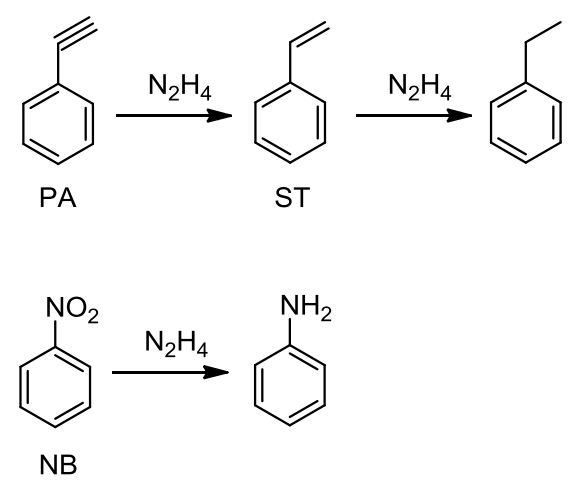

Scheme 1. Reduction of phenylacetylene (PA) and nitrobenzene (NB) by hydrazine. ST: styrene

\section{Table 2}

Reduction of phenylacetylene (PA) by hydrazine over nitrogen-doped AC in the presence of different amounts of nitrobenzene (NB)

\begin{tabular}{ccccc}
\hline Entry & Amount of NB & Conversion of & Conversion of & Selectivity to \\
& $\left(\mathrm{cm}^{3}\right)$ & $\mathrm{NB}(\%)$ & $\mathrm{PA}(\%)$ & ST $(\%)$ \\
\hline
\end{tabular}

\begin{tabular}{ccccc}
\hline \multicolumn{2}{c}{ (a) In the absence of catalyst } & & & \\
1 & 0 & - & 4.2 & 84 \\
2 & 0.5 & 3.5 & 8.1 & 83 \\
3 & 1.0 & 2.1 & 7.6 & 80 \\
4 & 1.5 & 1.3 & 7.0 & 82 \\
5 & 2.0 & 1.4 & 7.1 & 80 \\
\hline (b) In the presence of catalyst & & & \\
6 & 0 & - & 4.5 & 87 \\
7 & 0.5 & 22 & 15 & 73 \\
8 & 1.0 & 14 & 15 & 75 \\
\hline
\end{tabular}




\begin{tabular}{ccccc}
\hline 9 & 1.5 & 12 & 13 & 78 \\
10 & 2.0 & 11 & 14 & 76 \\
\hline
\end{tabular}

Reaction conditions: catalyst $10 \mathrm{mg}$, phenylacetylene $0.25 \mathrm{~cm}^{3}$, additive + ethylene glycol $2.0 \mathrm{~cm}^{3}$, hydrazine $6.0 \mathrm{~cm}^{3}, \mathrm{~N}_{2} 0.2 \mathrm{MPa}, 100^{\circ} \mathrm{C}, 20 \mathrm{~min}$.

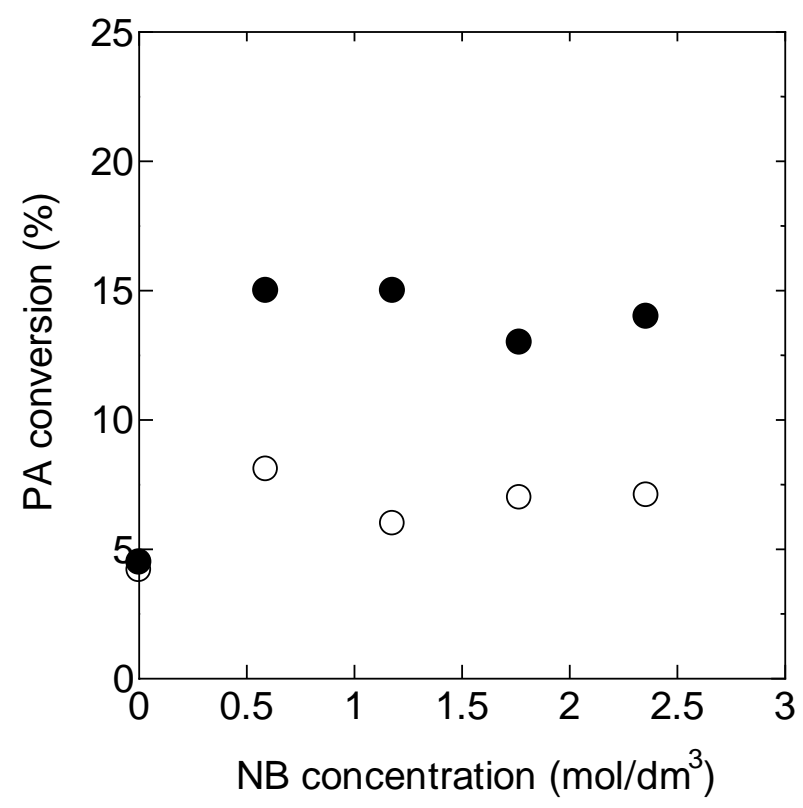

Fig. 1. Influence of nitrobenzene (NB) concentration on phenylacetylene (PA) conversion in PA reduction by hydrazine in the presence $(\bullet)$ and absence $(\circ)$ of nitrogen-doped carbon catalyst. Reaction conditions: catalyst $10 \mathrm{mg}$, phenylacetylene $0.25 \mathrm{~cm}^{3}$, additive + ethylene glycol $2.0 \mathrm{~cm}^{3}$, hydrazine $6.0 \mathrm{~cm}^{3}, \mathrm{~N}_{2} 0.2 \mathrm{MPa}, 100^{\circ} \mathrm{C}, 20 \mathrm{~min}$.

Fig. 2 shows the time-course of the reduction of a mixture of phenylacetylene and nitrobenzene. The amount of phenylacetylene consumed increased with time but became levelled off when a large amount of nitrobenzene disappeared. This also indicates that nitrobenzene is involved in the promoted reduction of phenylacetylene by hydrazine over nitrogen-doped AC catalyst. 


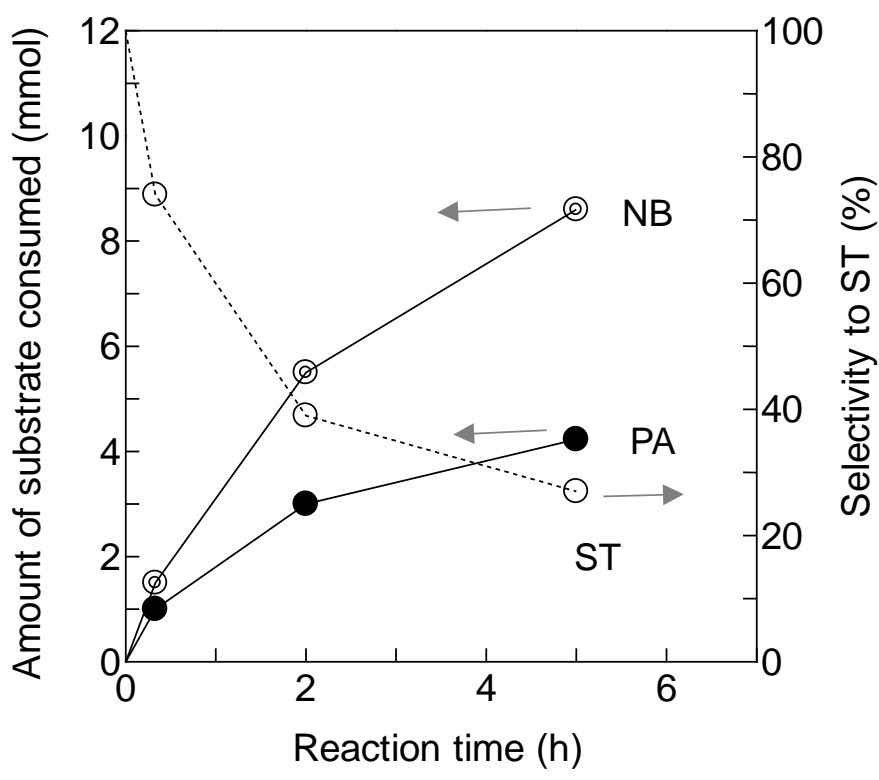

Fig. 2. Changes of the amounts of phenylacetylene (PA) and nitrobenzene (NB) consumed with time in the reduction by hydrazine. ST: styrene. Reaction conditions: catalyst $10 \mathrm{mg}$, phenylacetylene 0.25 $\mathrm{cm}^{3}$, nitrobenzene $1.0 \mathrm{~cm}^{3}$, ethylene glycol $2.0 \mathrm{~cm}^{3}$, hydrazine $6.0 \mathrm{~cm}^{3}, \mathrm{~N}_{2} 0.2 \mathrm{MPa}, 100^{\circ} \mathrm{C}$.

As described previously [10], the surface nitrogen and oxygen species are involved in the generation of active sites for the reduction of nitrobenzene by hydrazine. The abovementioned results demonstrate that, for the nitrogen-doped $\mathrm{AC}$ catalyst, the reduction of phenylacetylene is assisted by nitrobenzene co-existing in the reaction mixture. The reduction of nitrobenzene should start with the adsorption on the catalyst through its nitro group and phenylacetylene should also be adsorbed in the presence of nitrobenzene. It is thus suggested that interactions between the two substrates, phenylacetylene and nitrobenzene, occur and allow the former to be adsorbed and reduced on the surface of nitrogen-doped AC catalyst. Possible interactions among the two substrates and the catalyst surface are illustrated in Scheme 2. Nitrobenzene may be adsorbed with its nitro group through interactions with the surface $\mathrm{N}, \mathrm{O}$, and/or $\mathrm{C}$ species and the adsorption of phenylacetylene is allowed to occur through interactions between its $\mathrm{C}-\mathrm{C}$ and $\mathrm{O}-\mathrm{N}$ bonds, in which $\mathrm{O}$ and $\mathrm{N}$ originate from the nitrobenzene and the $\mathrm{N}$ species doped on the surface. This might also activate the reactivity of $\mathrm{C}-\mathrm{C}$ bond of phenylacetylene. In the case of phenylacetylene alone, it should not be adsorbed on the surface of nitrogen- and oxygen-doped AC catalyst. The presence of neighboring $\mathrm{N}$ and $\mathrm{O}$ species on the surface of $\mathrm{AC}$, as illustrated in Scheme 2, is likely 
because the pretreatment with hydrogen peroxide can assist the doping of nitrogen by the subsequent treatment with ammonia [12]. That is, surface $\mathrm{O}$ species pre-doped on the surface of $\mathrm{AC}$ is beneficial for the doping of $\mathrm{N}$ species. It was previously reported that gaseous $\mathrm{H}_{2}$ was unable to reduce nitrobenzene over nitrogen-doped AC catalysts [10]. Recently Zhang et al. have suggested that the cleavage of $\mathrm{N}-\mathrm{H}$ bond of $\mathrm{N}_{2} \mathrm{H}_{4}$ is important in the transfer hydrogenation of aromatic nitro compounds with $\mathrm{N}_{2} \mathrm{H}_{4}$, yielding hydride and proton species for which basic and acidic sites on the surface of catalyst are crucial [14]. There is a possibility that such hydride and proton species are formed on the surface of nitrogen-doped $\mathrm{AC}$ catalyst, reducing nitrobenzene and phenylacetylene. The surface $\mathrm{N}$ and/or $\mathrm{O}$ species should also be significant for the adsorption of $\mathrm{N}_{2} \mathrm{H}_{4}$ and/or the formation of $\mathrm{N}_{\mathrm{x}} \mathrm{H}_{\mathrm{y}}$ and $\mathrm{H}^{+}$ species. This is because the parent untreated AC material is less active for the reduction of nitrobenzene and nitrostyrene with hydrazine [10].
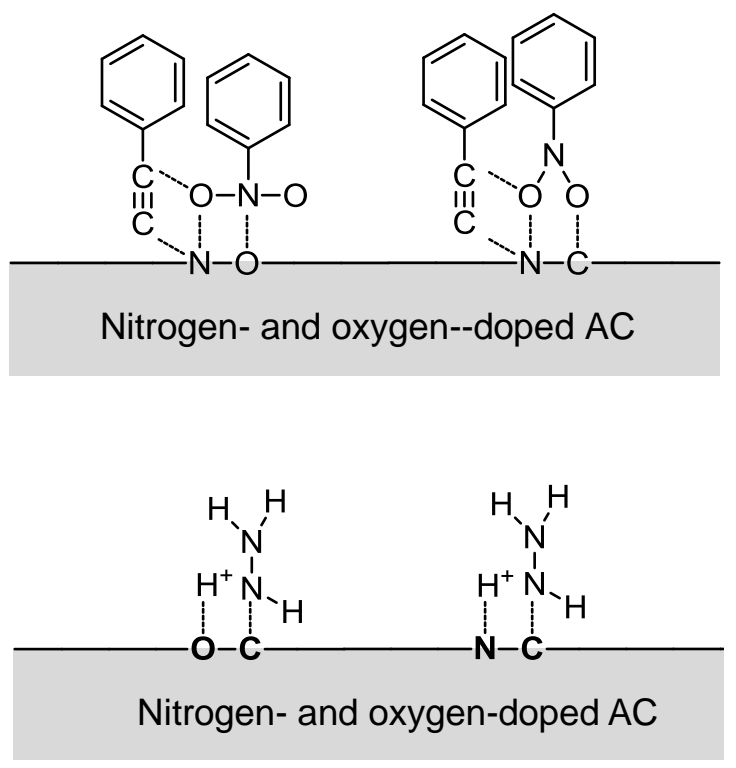

Scheme 2. Possible nitrobenzene-assisted adsorption of phenylacetylene and activation of hydrazine on the surface of nitrogen- and oxygen-doped AC catalyst

The possibility of the above-mentioned interactions among the reacting species was examined by FTIR - ATR spectroscopy [13]. The spectra collected at room temperature are presented in Fig. 3, which indicate that bending vibration of $-\mathrm{C} \equiv \mathrm{C}-\mathrm{H}$ of phenylacetylene and stretching vibration of $-\mathrm{NO}_{2}$ of nitrobenzene occur at the same frequencies for their neat 
and mixture samples. Therefore, appreciable interactions are unlikely to operate between the two reacting molecules in the absence of other reacting species. The strength (reactivity) of $\mathrm{C} \equiv \mathrm{C}$ bond of phenylacetylene is not affected by coexisting nitrobenzene in the liquid phase and vice versa. In the absence of catalyst, the reduction of phenylacetylene with hydrazine can be assisted to some extent by nitrobenzene (Table 2, Fig. 1). Phenylacetylene should be activated by nitrobenzene in the presence of hydrazine. Some interactions might occur for phenylacetylene with an intermediate that is formed through partial reduction of nitrobenzene and/or with hydrazine and/or other species formed from hydrazine. However, such an activation of phenylacetylene in the homogeneous liquid phase is not so significant as compared to its activation on the nitrogen-doped AC catalyst (Fig. 1, Scheme 2). The catalyst is crucial for the nitrobenzene-assisted promotion of the reduction of phenylacetylene by hydrazine. Unfortunately, FTIR-ATR measurement failed to detect intermediate/complex species in the liquid phase for a mixture of phenylacetylene, nitrobenzene, and hydrazine in a volume ratio of $1: 1: 1$ at a reaction temperature of $100^{\circ} \mathrm{C}$. Such intermediate/complex species should rapidly change to the final products of styrene, ethylbenzene, and aniline under the conditions examined.
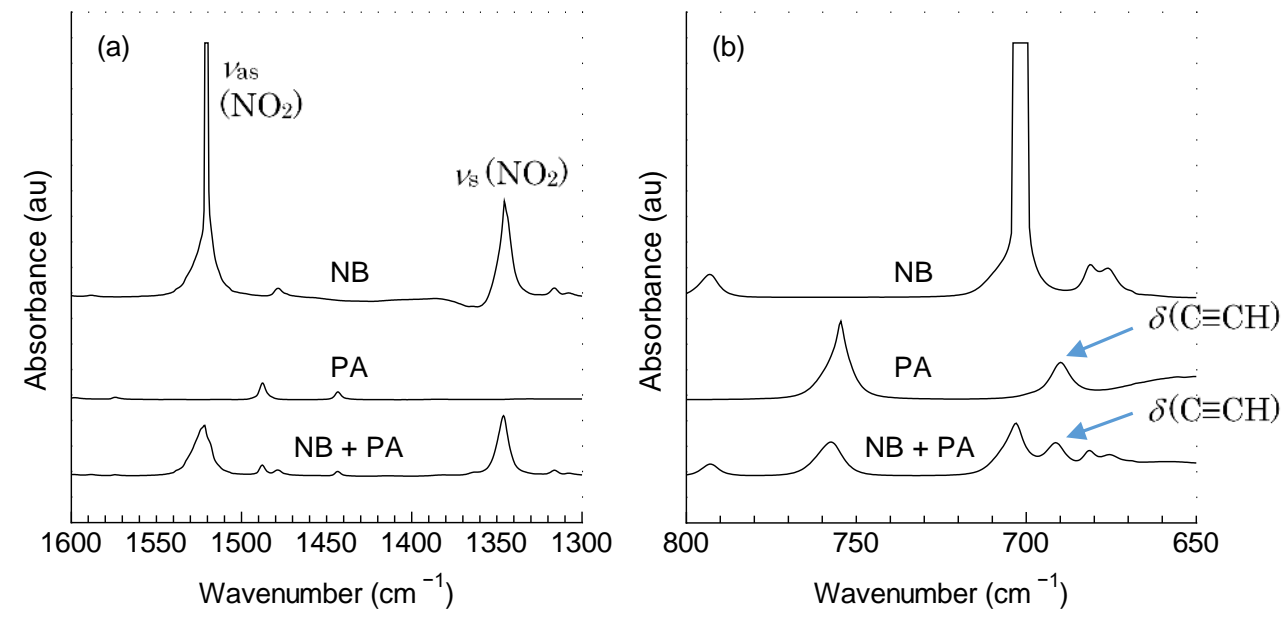

Fig. 3. FTIR - ATR spectra of nitrobenzene (NB), phenylacetylene (PA), and a mixture of NB and PA in 1:1 in volume for (a) $-\mathrm{NO}_{2}$ stretching vibration [15] and (b) $-\mathrm{C} \equiv \mathrm{C}-\mathrm{H}$ bending vibration [15].

Recently, Medlin et al. reported an interesting result that the product selectivity in hydrogenation of $\alpha, \beta$-unsaturated aldehydes like cinnamaldehyde over a $\mathrm{Pt} / \mathrm{Al}_{2} \mathrm{O}_{3}$ catalyst 
was controlled by thiolate modifiers introduced on its surface [16]. The modifiers can control the orientation of CAL adsorption on Pt and promote the hydrogenation of its carbonyl group, enhancing the selectivity to the corresponding unsaturated alcohol. The enhancement in the selectivity results from interactions between the modifiers and the substrates on the surface of supported Pt particles. In our case of the reduction on nitrogen-doped AC catalyst, the interactions between nitrobenzene and phenylacetylene molecules on its surface allow the reduction of phenylacetylene and the surface $\mathrm{N}$ and/or $\mathrm{O}$ species should be significant for these interactions to occur.

\section{Conclusions}

An interesting catalytic function of nitrogen- and oxygen-doped AC material is demonstrated in the nitrobenzene-promoted reduction of phenylacetylene with hydrazine. Synergistic effects of nitrobenzene and surface nitrogen and/or oxygen species promote the adsorption of phenylacetylene and thus allow its reduction although it is not reduced in the absence of nitrobenzene. The present results would provide a new method for modifying and controlling a chemical reaction over nitrogen- and oxygen-doped metal-free carbon catalysts.

\section{Acknowledgement}

The authors are thankful to Y. Onodera for his help in FTIR - ATR measurements.

\section{References}

[1] L. Liu, Y. Zhu, M. Su, Z. Yuan, ChemCatChem 7 (2015) 2765-2787.

[2] O. Y. Podyacheva, Z. R. Ismagilova, Catal. Today 249 (2015) 12-22.

[3] K. N. Wood, R. O’Hayer, S. Pylypenko, Energy Environ. Sci. 7 (2014) 1212-1249.

[4] W. Shen, W. Fan, J. Mater. Chem. A 1 (2013) 999-1013.

[5] D. Su, J. Zhang, B. Frank, A. Thomas, X. Wang, J. Paraknowitsch, R. Schlögl, ChemSusChem 3 (2010) 169-180. 
[6] A. Thomas, A. Fischer, F. Goettmann, M. Antonietti, J. O. Müller, R. Schlögl, J. M. Carlsson, J. Mater. Chem. 18 (2008) 4893-4908.

[7] T. Ikeda, M. Boero, S. F. Huang, K. Terakura, M. Oshima, J. Ozaki, J. Phys. Chem. C 112 (2008) 14706-14709.

[8] N. Kan-nari, S. Okamura, S. Fujita, J. Ozaki, M. Arai, Adv. Synth. Catal. 352 (2010) $1476-1484$.

[9] S. Fujita, A. Katagiri, H. Watanabe, S. Asano, H. Yoshida, M. Arai, ChemCatChem 7 (2015) 2965-2970.

[10] S. Fujita, H. Watanabe, A. Katagiri, H. Yoshida, M. Arai, J. Mol. Catal. A Chem. 393 (2014) 257-262.

[11] S. Fujita, K. Yamada, A. Katagiri, H. Watanabe, H. Yoshida, M. Arai, Appl. Catal. A Gen. 488 (2014) 171-175.

[12] H. Watanabe, S. Asano, S. Fujita, H. Yoshida, M. Arai, ACS Catal. 5 (2015) 2886-2894.

[13] H. Yoshida, K. Kato, J. Wang, X. Meng, S. Narisawa, S. Fujita, Z. Wu, F. Zhao, M. Arai, J. Phys. Chem. C 115 (2011) 2257-2267

[14] C. Zhang, J. Lu, M. Li, Y. Wang, Z. Zhang, H. Chen, F. Wang, F. Green Chem. 18 (2016) 2435-2442.

[15] K. Nakanishi, P. A. Solomon, Infrared Absorption Spectroscopy, 2nd ed., Holden-Day, San Francisco, 1977, pp. 45, 184.

[16] K. R. Kahsar, D. K. Schwartz, J. W. Medlin, J. Am. Chem. Soc. 136 (2014) 520-526. 


\section{Graphical Abstract}

Nitrobenzene-assisted reduction of phenylacetylene with hydrazine over nitrogendoped metal-free activated carbon catalyst: Significance of interactions among substrates and catalyst

Shin-ichiro Fujita, Sayaka Asano, Masahiko Arai

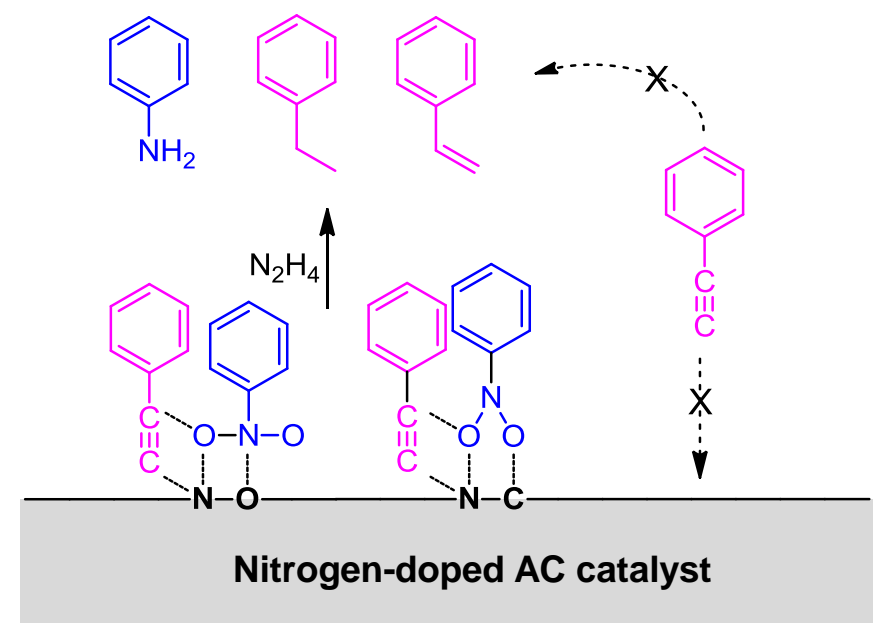

The reduction of phenylacetylene by hydrazine over nitrogen- and oxygen-doped AC catalyst can be assisted by coexisting reducible nitrobenzene. 